\title{
Abordagem nas doenças sexualmente transmissíveis
}

\author{
Approach in sexually transmitted diseases
}

\author{
Walter Belda Junior ${ }^{1}$
}

\author{
Ricardo Shiratsu ${ }^{2}$
}

\author{
Valdir Pinto ${ }^{3}$
}

\begin{abstract}
Resumo: As doenças sexualmente transmissíveis estão entre os problemas de saúde pública mais comuns em todo o mundo. Entre suas consequências estão a infertilidade feminina e masculina, a transmissão de mãe para filho, determinando perdas gestacionais ou doença congênita, e o aumento do risco para a infecção pelo HIV. Dessa forma, este guideline tem o objetivo de contribuir para melhorar a qualidade de atenção às pessoas com infecções sexualmente transmissíveis mais frequentes no Brasil, trazendo de forma didática e concreta o estado atual dos conhecimentos para os dermatologistas e médicos em geral que atuam no atendimento dessas pessoas e as principais recomendações para o diagnóstico e tratamento das doenças sexualmente transmissíveis mais recorrentes.

Palavras-chave: Cancróide; Doenças sexualmente transmissíveis; Doenças sexualmente transmissíveis/diagnóstico; Doenças sexualmente transmissíveis/etiologia; Doenças sexualmente transmissíveis/terapia; Gonorréia; Granuloma inguinal; Linfogranuloma venéreo

Abstract: Nowadays, sexually transmitted diseases are one of the most common public health issues. Among its consequences are the possibility of transmission from mother to baby - which may cause miscarriages and congenital disease, male and female infertility, and the increase of HIV infection risk. Therefore, the main goal of these guidelines is to contribute to the improvement of the treatment for sexually transmitted diseases patients by presenting to the medical community how today's science stands on the matter and also what the recommendation for diagnosing and treating a patient are.

Keywords: Chancroid; Gonorrhea; Granuloma inguinale; Lymphogranuloma venereum; Sexually transmitted disease; Sexually transmitted disease/diagnosis; Sexually transmitted disease/etiology; Sexually transmitted disease/therapy
\end{abstract}

\section{INTRODUÇÃO}

Em 1999, a Organização Mundial da Saúde (OMS) estimou o total de 340 milhões de casos novos por ano de doenças sexualmente transmissíveis (DST) curáveis em todo o mundo, entre indivíduos com idade de 15 e 49 anos, 10 a 12 milhões desses casos no Brasil. Outros tantos milhões de DST não curáveis (virais), incluindo o herpes genital, infecções pelo papilomavírus humano, hepatite $\mathrm{B}$ e infecção pelo HIV ocorrem anualmente. ${ }^{1}$

Das mulheres com infecções não tratadas por gonorreia/clamídia, 10 a $40 \%$ desenvolvem doença inflamatória pélvica (DIP). Destas, mais de $25 \%$ se tor- narão inférteis, lembrando que a estimativa da taxa de infertilidade por causas não infecciosas varia de três a $7 \%$. Estudos realizados em países desenvolvidos indicam que mulheres que tiveram DIP têm probabilidade seis a 10 vezes maior de desenvolver gravidez ectópica, que contribui com mais de $15 \%$ das mortes maternas. ${ }^{2}$

Abortos espontâneos, natimortos, baixo peso ao nascer, infecção congênita e perinatal, estão associadas às DST não tratadas em gestantes. ${ }^{3}$ Entre homens, a clamídia tem-se tornado importante causa de infertilidade quando não tratada adequadamente. ${ }^{4-6}$

Apesar disso, as doenças sexualmente transmis-

\footnotetext{
Aprovado pelo Conselho Editorial e aceito para publicação em 20.02.09.

* Trabalho realizado no Departamento de Dermatologia da Faculdade de Medicina da Universidade de São Paulo (FMUSP) - São Paulo (SP), Brasil. Conflito de interesse: Nenhum / Conflict of interest: None

Suporte financeiro: Nenhum / Financial funding: None

1 Responsável pelo Departamento de Doenças Sexualmente Transmissíveis/Aids da Sociedade Brasileira de Dermatologia. Livre-docente em dermatologia pela Universidade Estadual de Campinas (Unicamp). Professor-assistente doutor do Departamento de Dermatologia da Faculdade de Medicina da Universidade de São Paulo (FMUSP) - São Paulo (SP), Brasil.

Professor-assistente voluntário do Departamento de Dermatologia da Universidade Federal de São Paulo (UNIFESP) - São Paulo (SP), Brasil.

Programa Nacional de Controle das Doenças Sexualmente Transmissíveis do Ministério da Saúde.

C2009 by Anais Brasileiros de Dermatologia
} 
síveis só voltaram a readquirir importância como problema de saúde pública após a epidemia de Aids. Estudos demonstraram que pessoas com DST e infecções genitais não ulcerativas têm risco aumentado de cinco a 10 vezes de se infectar pelo HIV, o que sobe para 18 vezes se a doença cursa com lesões ulceradas.

Por outro lado, se o portador de HIV também for portador de alguma DST, mais facilmente transmitirá o HIV a seus parceiros. A concentração média de HIV no líquido seminal é oito vezes maior em homens com uretrite, sem diferença na concentração sanguínea. Após o tratamento a concentração seminal volta a ser comparável. ${ }^{8} \mathrm{O}$ HIV também está presente na secreção cervicovaginal em frequência duas vezes maior entre mulheres com gonorreia, três vezes maior na presença de clamídia e quatro vezes maior se existe ulceração no colo uterino ou na vagina. ${ }^{9}$ A vaginose bacteriana de origem endógena dobra o risco de infecção pelo HIV e tem importantes implicações no período gestacional, aumentando o risco de prematuridade e infecção puerperal. ${ }^{10-12}$

As DST de notificação compulsória são Aids, HIV na gestante e criança exposta, sífilis na gestação e sífilis congênita. Para as outras DST, não há sistema de notificação compulsória, e a ausência de estudos de base populacional dificulta a visibilidade do problema e a implantação de intervenções prioritárias e avaliação de sua efetividade. ${ }^{13}$

\section{PRINCIPAIS SÍNDROMES CLÍNICAS - SÍFILIS ADQUIRIDA}

Doença infecciosa crônica, de transmissão sexual e eventualmente transplacentária. Caracterizase por longos períodos de silêncio clínico e pela capacidade de atingir múltiplos sistemas orgânicos, produzindo lesões cutâneas, mucosas, cardiovasculares e nervosas.

\section{Etiologia}

O Treponema pallidum é micro-organismo desprovido de membrana celular, pequeno $(5 \times 15 \times 0,2 \mathrm{~nm})$, fino, de espiras regulares e em número não superior a 12 , com extremidades afiladas. Possui movimentos de rotação, flexão e contração, assim como de translação. Não é visível ao microscópio óptico, exceto quando tingido pela técnica de impregnação argêntica (Fontana).

\section{Epidemiologia}

É doença universal que atinge todas as classes sociais. A fonte de infecção é exclusivamente humana, e são contagiosas as manifestações da sífilis primária e secundária. Não confere imunidade, sendo portanto possível a reinfecção e sobreinfecções. São mais acometidos os jovens, principalmente entre 15 e 25 anos, por ter atividade sexual mais recorrente. ${ }^{14,15}$

\section{Transmissão}

Sua transmissão se faz por contato direto com lesões abertas, por transfusão de sangue contaminado na sífilis adquirida e por via transplacentária na sífilis congênita. $O$ treponema é capaz de penetrar via pele e mucosas íntegras, porém sua penetração é muito facilitada quando há soluções de continuidade. Multiplica-se rapidamente no epitélio infectado e, por via linfática, atinge os gânglios regionais, onde igualmente se multiplica com rapidez. Sua disseminação também é imediata por via hematogênica. Dessa forma, invade todo o organismo, generalizando-se a infecção ao longo de poucas horas, mesmo quando a sintomatologia é local. Existem relatos de inoculações acidentais por manipulação de lesões contaminadas em médicos, dentistas e técnicos de laboratório.

\section{Manifestações clínicas}

A primeira manifestação da sífilis adquirida é o cancro duro, cujo período de incubação varia de duas a quatro semanas. Quando plenamente desenvolvida, mostra-se como lesão exulcerada, redonda ou oval, de fundo limpo e rosado, granulomatoso e cor de carne, que emana serosidade transparente rica em treponemas, sem fenômenos inflamatórios adjacentes. Faz parte do quadro da sífilis primária a adenopatia satélite ao cancro, sempre presente e sem sinais flogísticos. A fase secundária caracteriza-se por roséola sifilítica, condilomas acuminados, alopecia em clareira e micropoliadenopatia generalizada que acompanha as lesões cutâneo-mucosas e pode ser observada nas regiões cervicais, supraclaviculares, axilares, epitrocleares e inguinocrurais. A sífilis tardia sintomática surge após períodos variáveis de latência, desde dois meses até 30 anos. Compreende desde lesões cutâneas de prognose benigna até lesões neurológicas, cardiovasculares e viscerais. As lesões cutâneas surgem em média entre dois e sete anos após o secundarismo.16

\section{Diagnóstico laboratorial \\ Exame de campo escuro}

Das provas diretas é a superior, pois permite a observação do Treponema pallidum vivo, móvel, com todas as suas características morfodinâmicas, executando movimentos de rotação, torção e flexão sem se deformar. A indicação máxima do campo escuro reside na sífilis primária.

A possibilidade de resultados negativos ao campo escuro pode estar relacionada a: ou geral;

- paciente com medicação treponemicida local

- cancro com mais de três semanas de evolução;

- amostra não representativa;

- processo não sifilítico.

Provas sorológicas 
Testes não treponêmicos (cardiolipídicos ou reaginas)

Esse tipo de prova detecta a presença de anticorpos inespecíficos (reaginas) no soro. Surgem habitualmente três a cinco semanas após o aparecimento do protosifiloma. São basicamente dois os tipos de provas: provas de floculação e reação de fixação de complemento. Das primeiras, a mais bem padronizada e mais largamente utilizada é a do VDRL (Venereal Disease Research Laboratory); e das últimas, a mais utilizada é a reação de Wassermann, além da RPR (Rapid Plasma Reagin). Os anticorpos detectados por essas técnicas são observáveis três semanas depois do aparecimento do cancro, aumentam seus títulos progressivamente até o máximo no período secundário, com praticamente $100 \%$ de positividade nessa fase. No período terciário a positividade é de aproximadamente $90 \%$.

Sendo reações não treponêmicas, não são específicas e, além de ser positivas em outras treponematoses como a bouba e pinta, podem estar presentes em enfermidades diferentes da sífilis, sendo, nesses casos, chamadas de reações sorológicas falso-positivas biológicas e tendo como principais causas:

1. Erro na realização da técnica

2. Causas agudas

- Mononucleose infecciosa

- Pneumonia viral

- Hepatite infecciosa

- Herpes simples e zoster

- Sarampo

- Linfogranuloma venéreo

- Vacinações (febre amarela e tifoide)

- Gravidez

3. Causas crônicas

- Artrite reumatoide

- Lúpus eritematoso sistêmico

- Anemia hemolítica autoimune

- Periarterite nodosa

- Tireoidite

- Hepatite crônica

- Hanseníase

- Tuberculose

- Leptospirose

- Malária

- Calazar

Testes treponêmicos

Para estabelecer diagnóstico definitivo de sífilis e devido às limitações que apresentam as provas não treponêmicas, faz-se necessária a confirmação mediante provas específicas com base na detecção de anticorpos contra o Treponema pallidum. ${ }^{1}$ Essas provas incluem o teste de imunofluorescência direta (FTAabs); o teste de imobilização do treponema (TPI); as provas de hemoaglutinação (TPHA) e mais recentemente os métodos de enzimaimunoensaio (EIA). ${ }^{16,17}$

As provas mais amplamente utilizadas são:

1. Prova de Imobilização do Treponema (TPI)

2. Prova de Fixação de Complemento com Proteína de Reiter (RPCF).

3. FTA-200

4. FTA-abs (Fluorescent Treponemal Antibody-absorbed Test)

5. Treponema pallidum Hemoaglutinação (TPHA). 6. IgM-TPHA

\section{Tratamento}

O Treponema pallidum é um dos micro-organismos mais sensíveis à penicilina, desaparecendo das lesões em 12-18 horas após sua administração sistêmica.

Dessa forma, a dose recomendada para o tratamento da sífilis recente (primária, secundária e latente com menos de um ano de evolução) é penicilina benzatina 2.400.000UI, intramuscular, dose única. Na sífilis tardia, latente, cutânea e cardiovascular, recomenda-se a penicilina benzatina 7.200.000UI, intramuscular, administrada em três doses semanais de 2.400.000UI. Nos casos de alergia à penicilina, são recomendados os seguintes esquemas alternativos: na sífilis recente: doxiciclina $100 \mathrm{mg} \mathrm{VO}, 12 / 12$ horas por 15 dias; tetraciclina $500 \mathrm{mg} \mathrm{VO}, 6 / 6$ horas por 15 dias; eritromicina 500mg VO, 6/6 horas por 15 dias; e ceftriaxone $250 \mathrm{mg}$ IM/dia por 10 dias. Na sífilis tardia, latente, cutânea e cardiovascular: doxiciclina 100mg VO, $12 / 12$ horas por quatro semanas; tetraciclina $500 \mathrm{mg}$ $\mathrm{VO}, 6 / 6$ horas por quatro semanas e, eritromicina $500 \mathrm{mg}$ VO, 6/6/horas por quatro semanas. Alguns autores sugerem o uso de azitromicina para o tratamento da sífilis, porém há relatos de falhas terapêuticas. ${ }^{18-20}$

\section{Controle de cura}

Os exames sorológicos deverão ser realizados aos três, seis e 12 meses após o tratamento. Admite-se que, se a titulação da sorologia não diminuir em quatro vezes na sífilis recente após três meses de tratamento ou aos seis meses na sífilis latente recente, ou ainda se persistirem os sinais e sintomas clínicos da enfermidade, deve-se aceitar o fracasso terapêutico ou a possibilidade de reinfecção. Nesse caso, antes de se instituir novo tratamento, deverão ser realizados a punção lombar e o exame do LCR. O exame do LCR também deverá ser efetuado sempre que ocorrer aumento de quatro vezes na titulação dos exames sorológicos. ${ }^{16}$

\section{- GONORREIA}

Enfermidade infectocontagiosa, pandêmica, inter-humana, produzida por diplococo (Neisseria gonorrboeae), de transmissão sexual, ainda que excep- 
cionalmente possa ocorrer contaminação indireta, e que não confere imunidade. Em geral trata-se de infecção de uretra ou colo uterino, que pode propagar-se para glândulas e órgãos vizinhos por via ascendente, sendo eventualmente a infecção local primitiva extragenital, produzindo quadros de conjuntivite, oftalmia, faringites e anoretite. Como qualquer processo infeccioso, nem sempre é localizada, pois, dependendo das condições imunológicas do hospedeiro, pode produzir septicemia, com manifestações gerais e sistêmicas.

\section{Epidemiologia}

Sua incidência é maior entre os 15 e 30 anos, não raramente sendo encontrada em idades inferiores ou muito superiores. Acomete ambos os sexos, com predominância do masculino.

\section{Agente etiológico}

A Neisseria gonorrhoeae é diplococo Gramnegativo, com 0,6 a $1 \mathrm{~m} \mu$ de diâmetro, reniforme, que se apresenta agrupado dois a dois, com as faces côncavas adjacentes. São aeróbios, imóveis, não formadores de esporos e sensíveis à maioria dos antissépticos usados atualmente. São organismos intracelulares e desprovidos de cápsula.

\section{Manifestações clínicas}

No homem as manifestações ocorrem após período de incubação médio de dois a cinco dias. Inicialmente surge sensação de formigamento ou prurido intrauretral, acompanhado de disúria. Dois a três dias após surge fluxo uretral mucoso, que rapidamente se torna mucopurulento, de coloração amareloesverdeada, com eliminação abundante e espontânea.

$\mathrm{Na}$ mulher a maioria dos casos encontra-se em quadros mais frustos, traduzidos apenas por endocervicite. $^{21}$

Complicações no homem:

- Balanopostite

- Litrites

- Cowperites

- Prostatite

- Epididimite

- Cistite

Complicações na mulher:

- Bartolinites

- Anexite

\section{- GONORREIA EXTRAGENITAL}

Oftálmica: O quadro caracteriza-se por conjuntivite, no início serosa, que se torna progressivamente purulenta, viscosa, amarelada, acompanhada de edema palpebral e conjuntival.
Retal: Os sintomas principais incluem tenesmo, prurido anal, evacuação dolorosa e secreção retal mucopurulenta. A retoscopia pode evidenciar mucosa arroxeada e edematosa, coberta de abundante supuração com múltiplas erosões.

\section{- FARINGITE GONOCÓCICA}

Acomete em média $10 \%$ a $20 \%$ dos indivíduos que praticam felação com portadores de uretrite gonocócica.

\section{Disseminada}

A disseminação hematogênica da gonorréia ocorre em 0,3 a $3 \%$ dos casos e afeta principalmente a pele e as articulações, e menos frequentemente as valvas cardíacas e o cérebro.

\section{Diagnóstico diferencial}

Deve ser feito com os processos provocados por diferentes agentes etiológicos, entre eles a Chlamydia trachomatis, Ureaplasma urealitycum, Trichomonas vaginalis, herpes vírus, Candida albicans, processos químicos, metabólicos (diabetes) e traumáticos (ordenha).

\section{Diagnóstico laboratorial}

1) Coloração de Gram: observam-se diplococos Gram-negativos intracelulraes. ${ }^{22}$ Apresenta sensibilidade de $95 \%$ nos homens e $50 \%$ para amostras cervicais e retais.

2) Cultura: são recomendados meios enriquecidos e seletivos, o que assegura o crescimento e desenvolvimento da neisseria. São necessários a esses meios atmosfera de $\mathrm{CO} 2$ variável de $3 \%$ a $5 \%$ e teor de umidade de $90 \%$ à temperatura de $35,5^{\circ} \mathrm{C}$ a $36,5^{\circ} \mathrm{C} . .^{23,24}$

Dos meios de cultura utilizados, os mais tradicionais são o Thayer-Martin modificado; o Martin Lewis e o NYC (New York City). ${ }^{25}$

\section{Tratamento}

Em virtude da grande capacidade de essas bactérias desenvolverem resistência, cromossômica e/ou plasmidial, aos diversos antibióticos utilizados em seu tratamento, faz-se necessária observação constante dos resultados terapêuticos obtidos no intuito de detectar eventuais falhas. Atualmente são recomendados para seu tratamento: Ofloxacina $400 \mathrm{mg}$ via oral em dose única; cefixima $400 \mathrm{mg}$ via oral em dose única; ciprofloxacina $500 \mathrm{mg}$ via oral em dose única; ceftriaxone $250 \mathrm{mg}$ intramuscular em dose única. Embora a partir de 2006 o Center for Disease Control and Prevention (CDC) não recomende mais a utilização de derivados quinolônicos no tratamento da gonorreia devido ao aumento progressivo de cepas resistentes nos EUA, esse fenômeno ainda é baixo no Brasil. ${ }^{26-29}$ 


\section{- CANCRO MOLE}

Doença sexualmente transmissível, de evolução aguda, causada por bacilo Gram-negativo e caracterizada clinicamente pela presença de ulcerações dolorosas, em número variado, de bordas irregulares e frequentemente envoltas por halo eritematoso vivo, localizadas em região genital, anal ou anogenital, acompanhadas ou não de adenopatia satélite.

\section{Epidemiologia}

Enfermidade cosmopolita com surtos em países industrializados, porém com maior prevalência na África, Oriente Médio e regiões tropicais e subtropicais da América do Sul. O reservatório natural parece ser exclusivamente o homem. Apresenta alta infectividade e baixa patogenicidade. Sua virulência é baixa, uma vez que se trata de infecção limitada à pele e a mucosas, não ocorrendo comprometimento sistêmico.

\section{Etiologia}

Trata-se de coco bacilo curto, da família Brucellaceae, gênero Haemophilus, espécie ducreyi. É bacilo Gram-negativo, intracelular, anaeróbico facultativo, com dimensões de um a $2 \mu \mathrm{m}$ por $0,5 \mu \mathrm{m}$, com extremidades arredondadas e desprovido de cápsula ou motilidade. Dispõe-se em cadeias simples ou duplas no interior de polimorfonucleares. Seu cultivo é difícil, crescendo moderadamente em meios de ágar-chocolate.

\section{Manifestações clínicas}

Apresenta curto período de incubação, oscilando entre quatro e sete dias, sendo raro seu aparecimento com menos de três ou mais de 10 dias. Iniciase como pequena pápula inflamatória envolta por halo eritematoso escuro, que rapidamente evolui para lesão vesicopustulosa que, ao se romper, resulta em lesão ulcerada, de base mole, rasa, com bordas irregulares, recoberta por exsudato necrótico purulento e envolta por halo eritematoso vivo. São lesões dolorosas e em número, forma e tamanho variados devido a sua característica de autoinoculação. Enfartamento ganglionar inguinal pode estar presente em até 50\% dos casos, geralmente unilateral, evoluindo dois terços desses casos com flutuação e fistulização, drenando material purulento através de fístula única, o que pode auxiliar no diagnóstico diferencial do linfogranuloma venéreo, em que a fistulização se faz através de múltiplos orifícios. ${ }^{30.32}$

\section{Diagnóstico diferencial}

Deve ser realizado basicamente com as demais úlceras genitais de origem infecciosa ou parasitária, entre elas o protosifiloma, que se caracteriza pela induração de sua base, geralmente única, indolor e de fundo limpo, com adenopatia regional não inflamatória sempre presente; o linfogranuloma venéreo no qual a adenopatia está sempre presente e é a manifestação maior dessa doença, apresentando fistulização através de inúmeros orifícios; a donovanose, na qual as úlceras são botonosas, indolores, de fundo limpo e sangram com extrema facilidade sem apresentar comprometimento ganglionar. Deve-se ainda diferenciá-lo das lesões do herpes genital, foliculites, impetigo, leishmaniose tegumentar americana, paracoccidioidomicose e pioderma genital (forma fagedênica).

\section{Diagnóstico laboratorial}

1) Coloração de Gram no material purulento obtido das úlceras, evidenciando-se bacilos Gramnegativos dispostos em colunas ou fila indiana.

2) Cultura: é bactéria de difícil cultivo, mesmo com a utilização de meios adequados, sendo os mais recomendados o de Nairobi, o de Johannesburg e o de ágar-chocolate enriquecido. A adição do antibiótico vancomicina ao meio de ágar-chocolate enriquecido tem por objetivo inibir o crescimento de bactérias Gram-positivas, geralmente presentes na amostra clínica coletada. ${ }^{33-35}$

\section{Tratamento}

Além dos cuidados locais, como a lavagem frequente com água e sabão, o paciente deverá ser reexaminado sete dias após o início da terapia, devendo, ao final desse período, apresentar melhora dos sintomas e da própria lesão. São indicadas para o tratamento as seguintes drogas: tianfenicol $500 \mathrm{mg} 8 / 8$ horas por cinco dias $;{ }^{36,37}$ tianfenicol granulado $5 \mathrm{~g}$ dose única; $;^{38,39}$ azitromicina $1 \mathrm{~g}$ via oral dose única; $;^{40}$ ceftriaxone $250 \mathrm{mg}$ intramuscular dose única; ${ }^{40}$ eritromicina $500 \mathrm{mg} \mathrm{6/6}$ horas por sete dias $;{ }^{40}$ ciprofloxacin 500mg dose única. ${ }^{40}$

\section{- LINFOGRANULOMA VENÉREO}

É doença infecto-contagiosa, de caráter inflamatório e invasivo, do trato urogenital causada pela infecção por Chlamydia trachomatis. Atualmente em várias partes do mundo, o linfogranuloma venéreo (LGV) tornou-se causa importante de doença anogenital entre homens que fazem sexo com outros homens. ${ }^{41}$

O LGV é causado pelos sorotipos invasivos L1, L2 e L3 da Chlamydia trachomatis, em contraste com os sorotipos de A-C desse agente, que causam infecções oculares, como o tracoma, e os sorotipos D-K, mais comuns, que causam infecções genitais. ${ }^{42}$

\section{Epidemiologia}

O LGV é doença relativamente rara em países industrializados, porém endêmica em partes da África, Ásia, América do Sul e Caribe. ${ }^{43}$

A incidência da infecção pela Chlamydia trachomatis após contato sexual é desconhecida, mas provavelmente é menor do que a da gonorréia e do 
cancróide. O pico de incidência da infecção é entre a segunda e a terceira década da vida, fase de atividade sexual mais recorrente. O período de transmissibilidade sexual pelos homens infectados é de cerca de três semanas após a lesão primária regredir. Entre as mulheres é desconhecido, mas provavelmente pode durar meses, uma vez que o colo do útero é passível de permanecer infectado indefinidamente. ${ }^{44}$

\section{Manifestações clínicas}

O período de incubação varia de três a 30 dias. ${ }^{45}$ São identificados, no curso clínico do LGV, três estádios da doença: primário (fases iniciais e lesões precoces), secundário (acometimento dos linfonodos regionais, denominado síndrome inguinal) e terciário (formas tardias ou sequelas da doença, ou síndrome anogenital) Entre duas e seis semanas após a lesão primária surgem adenomegalias femorais ou inguinais, geralmente unilaterais, dolorosas, com flutuação e que podem ter ruptura espontânea, com ou sem formação de fístulas. Duas adenomegalias separadas pelo ligamento de Poupart são características dessa doença. Homossexuais do sexo masculino e mulheres após intercurso sexual anal podem desenvolver proctite hemorrágica ou proctocolite nos estádios agudos do LGV. Os sintomas primários são prurido anal, secreção retal mucóide e dolorimento localizado; a seguir, a marca clínica do LGV anorretal é revelada: a secreção retal mucopurulenta. ${ }^{44}$ A proctite pode gerar ou diarréia, ou obstipação, sendo o tenesmo notado na forma clássica. O estádio terciário refere-se às complicações tardias que acometem o reto e a genitália, incluindo a elefantíase, mais comuns entre as mulheres e denominadas estiomene. ${ }^{46}$

\section{Diagnóstico diferencial}

O diagnóstico diferencial do LGV inclui outras doenças sexualmente transmissíveis, tais como sífilis, cancroide, proctite gonocócica, disenteria amebiana, doença de Crohn, retocolite ulcerativa e carcinoma anal.

\section{Diagnóstico laboratorial}

Atualmente o diagnóstico depende da sorologia ou da identificação da Chlamydia trachomatis em amostras clínicas apropriadas. Quando possível, o exame histopatológico de amostras de tecido retiradas por biópsia pode colaborar com o diagnóstico. O teste sorológico da fixação do complemento (FC) é gêneroespecífico e, assim, não distingue entre as espécies de clamídia, tais como Chlamydia trachomatis, Chlamydia psittaci e ao patógeno respiratório comum Chlamydia pneumoniae. O teste da microimunofluorescência (MIF) pode distinguir infecções com diferentes espécies de clamídias, porém não tem sido utilizado na rotina comercial, posto que requer microscópio de fluorescência e técnico habilidoso e treinado na técnica. Pode detectar anticorpos da classe IgM e IgG, espécie-específicos. MIF com título de IgG $>$ 1:128 sugere fortemente o diagnóstico de LGV. Dessa forma, a maioria dos exames sorológicos não distingue a infecção causada pelos diferentes sorotipos da Chlamydia trachomatis. ${ }^{43}$ A Chlamydia trachomatis pode ser isolada em cultura tecidual, usando-se a cepa de células HeLa-229 ou células de McCoy, técnica, porém, não amplamente disponível. De forma alternativa a Chlamydia trachomatis pode ser identificada pela microscopia de fluorescência direta, utilizando-se um conjugado de anticorpos monoclonais no material colhido do bulbão ou de ulceração. Esse método também requer microscópio de fluorescência e técnico treinado na execução e interpretação do exame. ${ }^{43}$

\section{Tratamento}

Tetraciclina $250 \mathrm{mg}$ via oral a cada seis horas ou doxiciclina $100 \mathrm{mg}$ via oral duas vezes ao dia, ambas durante 21 dias (primeira escolha); eritromicina $500 \mathrm{mg}$ via oral quatro vezes ao dia durante 21 dias (primeira escolha para grávidas e mulheres em aleitamento). ${ }^{45}$ Outras drogas podem ser utilizadas, o cloranfenicol, a rifampicina e o tianfenicol, por exemplo.

\section{- DONOVANOSE}

Doença bacteriana crônica, progressiva e indolente que acomete preferencialmente a pele $\mathrm{e}$ as mucosas das regiões genital e perigenital. É frequentemente associada à transmissão sexual, porém apresenta baixa infectividade.

\section{Etiologia}

Trata-se de cocobacilos Gram-negativos que se coram mais intensamente nas extremidades do que no centro, capsulados ou não, intracitoplasmáticos e imóveis (Calymmatobacterium granulomatis). Na forma de cocos arredondados, medem de 0,02 a $0,2 \mu \mathrm{m}$, e na forma bacilar de um a $2,5 \mu \mathrm{m}$ de comprimento. ${ }^{47,48}$

\section{Epidemiologia}

A doença é mais comum em negros e em indivíduos com nível social baixo e pouca noção de higiene. Sua distribuição geográfica é curiosa, sendo endêmica em países tropicais e subtropicais como PapuaNova Guiné, África do Sul (províncias KwaZulu/Natal e Transvaal Oriental), parte da Índia e da Indonésia, e entre os aborígines da Austrália. ${ }^{49}$

Trata-se de enfermidade que atinge quase exclusivamente adultos na faixa de 20-40 anos. Casos em crianças estão frequentemente associados ao contato com adultos infectados, não necessariamente por abuso sexual. 


\section{Manifestações clínicas}

O período de incubação é relatado variando de um a 360 dias, porém, lesões induzidas em voluntários sugerem período em torno de 50 dias.O reservatório é o homem. ${ }^{50}$

A manifestação clínica inicia-se como pápulas ou nódulos subcutâneos que podem evoluir com ulcerações superficiais. Crescem lentamente, sem causar dor, tornando-se bem definidas, granulomatosas, com caráter centrífugo e serpiginoso, sangrando com facilidade. Podem ser auto-inoculadas e múltiplas. Tipicamente não há adenite na donovanose. Além das regiões anal e perianal, as demais áreas de comprometimento extragenital são: lábios, gengivas, mucosa jugal, mandíbula, palato, faringe, laringe, pescoço, nariz, região oftálmica, couro cabeludo, tórax (sulcos inframamários), axilas, abdômen, braços, pernas, ossos (particularmente a tíbia). As lesões orais em geral são as mais frequentes, e a perda de dentes indica comprometimento ósseo. ${ }^{50,51}$ Disseminação para a cavidade abdominal, intestino, baço, fígado, pulmões, útero e ovários já foi relatada e é mais observada em áreas endêmicas.

\section{Diagnóstico laboratorial}

Citodiagnóstico: O material deve ser coletado, preferencialmente, das áreas de granulação ativa e sem infecção secundária, para a pesquisa dos corpúsculos de Donovan. \%. As colorações de Giemsa, de Leishman e de Wright poderão ser utilizadas.

Além do exame anatomopatológico, a microscopia eletrônica de transmissão pode ser utilizada para avaliar as características ultraestruturais da K. granulomatis de espécimes diferentes. A cultura do agente é difícil e não está disponível rotineiramente. $\mathrm{O}$ cocultivo com células em monocamada foi descrito utilizando monócitos humanos, células Hep-2 e macrófagos peritoniais de camundongos. ${ }^{52}$ As técnicas de detecção gênica por reação em cadeia da polimerase (PCR), que permitiram a reclassificação do agente da donovanose, têm sua aplicação diagnóstica restrita a programas de erradicação da doença.53,54

\section{Tratamento}

Não há consenso sobre a indicação do melhor tratamento para a donovanose.

São recomendados os seguintes esquemas terapêuticos: 1) azitromicina $1 \mathrm{~g}$ via oral no primeiro dia, seguida de $500 \mathrm{mg}$ via oral/dia ou doxiciclina $200 \mathrm{mg}$ via oral/dia até a cura clínica. 2) doxiciclina $200 \mathrm{mg}$ via oral/dia até a cura clínica. 3) eritromicina $2 \mathrm{~g}$ via oral/dia até a cura clínica. 4) tetraciclina $2 \mathrm{~g}$ via oral/dia até a cura clínica. 5) sulfametoxazol/trimetoprim (400/800) dois comprimidos via oral duas vezes ao dia por no mínimo 14 dias. Eventualmente outros antibióticos podem ser utilizados com respostas terapêu- ticas satisfatórias, como ceftriaxone, norfloxacin, trovofloxacin e tianfenicol. ${ }^{49,50,55-57}$ Para gestantes e pacientes HIV-positivos deve-se avaliar a adição do aminoglicosídeo desde o início do tratamento.

\section{Ações essenciais complementares}

Incluem as seguintes medidas gerais:

1) Aconselhar e oferecer a realização de sorologias anti-HIV, VDRL e hepatite B e C.

2) Vacinar contra hepatite B se o paciente tiver menos de 30 anos de idade.

3) Interromper as relações sexuais até a conclusão do tratamento e desaparecimento dos sintomas.

4) Enfatizar o uso constante de preservativos.

$\mathrm{Na}$ impossibilidade de se estabelecer o diagnóstico etiológico correto do processo recomenda-se a utilização da abordagem sindrômica preconizada pelo Ministério da Saúde, abaixo explicitada.

Abordagem sindrômica nas úlceras genitais Fluxograma para úlceras genitais (Figura 1)

Para o primeiro episódio de herpes genital, iniciar o tratamento o mais precocemente possível com aciclovir $200 \mathrm{mg}, 4 / 4 \mathrm{~h}$, cinco vezes por dia por sete dias ou $400 \mathrm{mg}$ via oral, $8 / 8$ horas por sete dias, ou valaciclovir $1 \mathrm{~g}$ via oral de $12 / 12$ horas por sete dias, ou famciclovir $250 \mathrm{mg}$ via oral, $8 / 8$ horas por sete dias. Nas recorrências de herpes genital iniciar o tratamento precocemente com aciclovir $400 \mathrm{mg}$ via oral, $8 / 8$ horas por cinco dias ou valaciclovir $500 \mathrm{mg}$ via oral, $12 / 12$ horas por cinco dias, ou famciclovir $125 \mathrm{mg}$ via oral, 12/12 horas por cinco dias.

$\mathrm{Na}$ ausência de lesões vesiculosas, recomendase o tratamento presuntivo para as duas causas mais frequentes de ulcera genital, a sífilis primária e o cancro mole, com penicilina $\mathrm{G}$ benzatina 2,4 milhões UI,

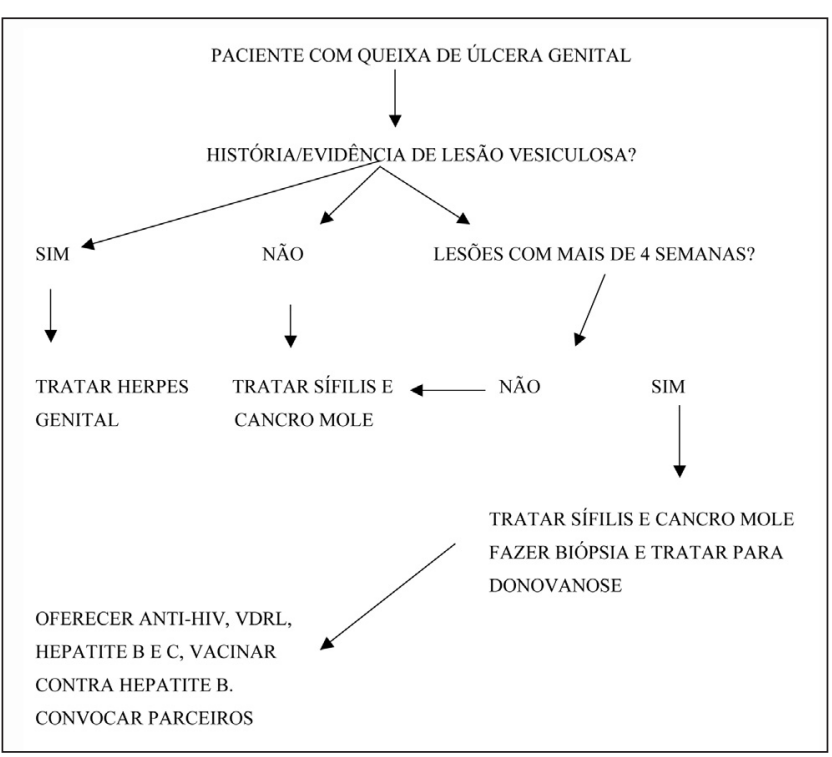

Figura 1: Fluxograma para úlceras genitais 
intramuscular em dose única + azitromicina $1 \mathrm{~g}$ via oral em dose única ou ciprofloxacina $500 \mathrm{mg}$ via oral, $12 / 12$ horas por três dias, ou estearato de eritromicina $500 \mathrm{mg}$ via oral, $6 / 6$ horas por sete dias.

Se as lesões tiverem mais de quatro semanas de duração, deve-se suspeitar de donovanose, linfogra- nuloma venéreo ou neoplasia. Encaminhar o paciente ou, se houver condições, realizar biópsia para investigação. Simultaneamente iniciar tratamento para donovanose com doxiciclina $200 \mathrm{mg} /$ dia via oral até cura clínica ou azitromicina $1 \mathrm{~g}$ via oral dose única, seguida por $500 \mathrm{mg}$ via oral/dia por três semanas.

\section{REFERÊNCIAS}

1. World Health Organization. Guidelines for the management of sexually transmitted infection. Geneva: Switzerland; 2003. 89p.

2. World Health Organization. Global strategy for prevention and control of sexually transmitted infections:2006 -2015. Geneva: Switzerland; 2007. 60p.

3. Gutman L. Gonococcal diseases in infants and children. In: Holmes KK, Mardh P-A, Sparling PF, Weisner PJ, Cates W Jr, Lemon SM, et al., eds. Sexually transmitted diseases. New York: McGraw-Hill Inc; 1999. p.1146.

4. Karinen L, Pouta A, Hartikainen AL, Bloigu A, Paldanius M, Leinonen M, et al. Association between Chlamydia trachomatis antibodies and subfertility in the Northern Finland Birth Cohort 1966 (NFBC 1966), at the age of 31 years. Epidemiol Infect. 2004;132:977-84.

5. Mardh PA. Tubal factor infertility, with special regard to chlamydial salpingitis. Curr Opin Infect Dis.

2004; 17:49-52.

6. Eley A, Pacey AA, Galdiero M, Galdiero M, Galdiero F. Can Chlamydia trachomatis directly damage your sperm? Lancet Infect Dis. 2005;5:53-7.

7. Fleming DT, Wasserheit JN. From epidemiological synergy to public health policy and practice: the contribution of other sexually transmitted diseases to sexual transmission of HIV infection. Sex Transm Infect. 1999; 75:3-17.

8. Cohen MS, Hoffman IF, Royce RA, Kazembe P, Dyer JR, Daly CC, et al. Reduction of concentration of HIV-1 in semen after treatment of urethritis: implications for prevention of sexual transmission of HIV-1. AIDSCAP Malawi Research Group. Lancet. 1997;349:1868-73.

9. Ghys PD, Fransen K, Diallo MO, Ettiègne-Traoré V, Coulibaly IM, Yeboué KM, et al. The associations between cervicovaginal HIV shedding, sexually transmitted diseases and immunosuppression in female sex workers in Abidjan, Côte d'Ivoire. AIDS. 1997; 11:85-93.

10. Sewankambo N, Gray RH, Wawer MJ, Paxton L, McNaim $\mathrm{D}$, Wabwire-Mangen F, et al. HIV-1 infection associated with abnormal vaginal flora morphology and bacterial vaginosis. Lancet. 1997;350:546-50.

11. Klebanoff MA, Hauth JC, MacPherson CA, Carey JC, Heine RP, Wapner RJ, et al. Time course of the regression of asymptomatic bacterial vaginosis in pregnancy with and without treatment. Am J Obstet Gynecol. 2004;190:363-70.

12. Leitich $\mathrm{H}$, Bodner-Adler $\mathrm{B}$, Brunbauer $\mathrm{M}$, Kaider A, Husslein P. Bacterial vaginosis as a risk factor for preterm delivery: a meta-analysis. Am J Obstet Gynecol. 2003;189:139-47.

13. Ministério da Saúde. Manual de controle das doenças sexualmente transmissíveis. 4 ed. Brasília: UNESCO; 2006. 142p.

14. Morton RS. The treponematoses. In.: Rook A, Wilkinson DS, Ebling TJG, Champion RH, Burton L, eds. Textbook of Dermatology. 4th ed. Oxford: Blackwell Scientific Publications; 1986.

15. Rhodes AR, Luger AFH. Syphilis and treponematoses. In.: Fitzpatrick TB, Eisen AZ, Wolf K, Freedberg JM. Austen KF, eds. Dermatology in General Medicine. New York: Mcgraw Hill; 1987.

16. Rivitti EA. Sífilis adquirida. In: Belda Jr W. Doenças sexualmente transmissíveis. São Paulo: Atheneu; 1999. p.9-21.

17. Nogueira JM, Camarena JJ. Diagnóstico microbiológico de la sífilis del adulto y de la sífilis congênita. In: Vilata JJ, ed. Enfermedades de transmision sexual. Barcelona: JR Prous Editores; 1993.

18. Centers for Disease Control and Prevention. Azithromycin treatment failures in syphilis infections San Francisco, California; 2002-2003. MMWR Morb Mortal Wkly Rep. 2004;53:197-8.

19. Holmes KK. Azithromycin versus penicillin $G$ benzathine for early syphilis. N Engl J Med. 2005;353:1291-3.

20. Passos MRL, Benzaken AS, Coelho ICB, Rodrigues GHS, Dutra JC, Varella R, et al. Estudo de equivalência entre azitromicina e penicilina $\mathrm{G}$ benzatina no tratamento da sífilis. DST J Bras Doenças Sex Transm. 2004;16:52-66.

21. Olmos L, Vázquez JA. Infecciones gonocócicas. In: Vilata JJ, ed. Enfermedades de transmission sexual. Barcelona: JR Prous Editores; 1993.

22. Siqueira LFG. O laboratório nas doenças sexualmente transmissíveis. Bol Inf Union. 1984;9:4.

23. Martins Jr JE, Jackson RL. A biological environment chamber for the culture of Neisseria gonorrboeae. J Am New Dis Anal. 1975;2:28-30.

24. Siqueira LFG. O laboratório nas doenças sexualmente transmissíveis. Bol Inf Union. 1985;10:4-5.

25. Siqueira LFG, Melles HHB. Uretrites gonocócicas e não gonocócicas - diagnóstico laboratorial. In: Belda Jr W, ed. Doenças sexualmente transmissíveis. São Paulo: Atheneu; 1999. p.59-69.

26. Bauer HM, Mark KE, Samuel M, Wang SA, Weismuller P 
Moore D, et al. Prevalence of and associated risk factors for fluoroquinolone-resistant Neisseria gonorrboeae in California, 2000-2003. Clin Infect Dis. 2005;41:795-803.

27. Center for Disease Control and Prevention. Fluoroquinolone-resistance in Neisseria gonorrboeae, Hawaii, 1999 and decreased susceptibility to azithromycin in N. gonorrboeae. Missouri, 1999. MMWR Morb Mortal Wkly. 2000;49:833-7.

28. Ng LK, Sawatzky P, Martin IE, Booth S. Characterization of ciprofloxacin resistance in Neisseria gonorrboeae isolates in Canada. Sex Transm Dis. 2002;29:780-8.

29. Belda Jr W, Velho PENF, Arnone M, Fagundes LJ. Emergence of fluoroquinolone-resistant Neisseria gonorrhoeae in São Paulo - Brazil. Braz J Microbiol. 2007;38:293-5.

30. Ronald AR, Albritton WC. Chancroid and Haemophilus ducreyi. In: Holmes KK, Mardh PA, Sparling PF, ed. Sexually transmitted diseases. New York: McGraw-Hill Book Co; 1984. p.385-93.

31. Belda Jr W, Siqueira LFG. Cancro Mole. In: Doenças sexualmente transmissíveis. Belda Jr W, ed. São Paulo: Atheneu; 1999. p.47-51

32. Morse AS. Chancroid and haemophilus ducreyi. Clin Microbiol Rev. 1989;2:137-57.

33. Hammond GW, Lian CJ, Ronald AR. Comparison of specimens collections and laboratory techniques for isolation of Haemophilus ducreyi. J Clin Microbiol. 1978;39-43.

34. Hannah P, Green Wood JR. Isolation and rapid identification of Haemophilus ducreyi. J Clin Microbiol. 1982;16:861-4.

35. Shawar R, Sepulveda J, Clarrige JE. Use of the rapl D-ANA system and sodium polyanetholesulfonate disk susceptibility testing in identifying Haemophilus ducreyi. J Clin Microbiol. 1990;28:108-11.

36. Belda W, Santos Jr MFQ, Belda Jr W, Siqueira LFG, Fagundes LJ, Lombardi C. Novos rumos no tratamento do cancro mole - Experimentação clinica com thiamfenicol. An Bras Dermatol. 1984;59:147-9.

37. Belda Jr W, Santi CG, Mirandez AA. Tratamento do cancróide com tianfenicol. Rev Bras Med. 1985;42:204-5.

38. Belda W, Santos Jr MFQ, Siqueira LFG, Belda Jr W. Emprego do tianfenicol granulado em dose única de 5 $\mathrm{g}$ no tratamento do cancro mole. An Bras Dermatol. 1984;59:209-12.

39. Belda Jr W, Siqueira LF, Fagundes LJ. Thiamphenicol in the treatment of chancroid. A study of 1128 cases. Rev Inst Med Trop Sao Paulo. 2000;42:133-5.

40. Centers for Diseases Control and Prevention. Sexually transmitted diseases treatment guidelines. MMWR Morb. Mortal Wkly. 1993;42:20-2.

41. van Hal SJ, Hillman R, Stark DJ, Harkness JL, Marriott D. Lymphogranuloma venereum: an emerging anorectal disease in Australia. Med J Aust. 2007;187:309-10.

42. Herring A, Richens J. Lymphogranuloma venereum. Sex Transm Inf. 2006;82 Suppl 4:iv23-5.
43. Mabey D, Peeling RW. Lymphogranuloma venereum. Sex Transm Infect. 2002;78:90-2.

44. Ahdoot A, Kotler DP, Suh JS, Kutler C, Flamholz R. Lymphogranuloma venereum in human immunodeficiency virus-infected individuals in New York City. J Clin Gastroenterol. 2006;40:385-90.

45. Da Costa JB, Domingues D, Castro R, Exposto F. Genital ulcers caused by sexually transmitted diseases: current therapies, diagnosis and their relevance in HIV pandemy. Acta Med Port. 2006;19:335-42.

46. Gupta S, Ajith C, Kanwar AJ, Sehgal VN, Kumar B, Mete U. Genital elephantiasis and sexually transmitted infections - revisited. Int J STD AIDS. 2006;17:157-65.

47. Galarza C. Donovanosis. Dermatol Peru. 2000;10:35-8.

48. Fonseca A, Souza EM. Donovanose in Dermatologia Clínica. Rio de Janeiro: Guanabara Koogan; 1984. p.167-9.

49. Department of Health and Human Services. Centers for Disease Control and Prevention. Granuloma inguinale (donovanosis) in sexually transmitted diseases treatment guidelines. MMWR Morb Mortal Wkly. 2006;55:20-1.

50. O'Farrell N. Donovanosis. Sex Transm Infect. 2002;78:452-7.

51. Veeranna $S$, Raghu TY. Oral Donovanosis. Int J STD AIDS. 2002;13:855-6.

52. Kaimal S, Thappa DM. Methods of specimen collection for the diagnosis of STIs. Indian J Dermatol Venereol Leprol. 2007;73:129-32.

53. Richens J. Donovanosis (granuloma inguinale). Sex Transm Infect. 2006;82(Suppl4):iv21-2.

54. Mackay IM, Harnett NJ, Bastian I, Sriprakash KS, Siebert D, Sloots TP. Detection and discrimination of herpes simplex viruses, Haemophilus ducreyi, Treponema pallidum, and Calymmatobacterium (Klebsiella) granulomatis from genital ulcers. Clin Infect Dis. 2006; $42: 1431-8$.

55. Jardim ML, Melo ZO. Tratamento da donovanose com o tiamfenicol. An Bras Dermatol. 1990;65:93-4.

56. Ministério da Saúde. Secretaria de Vigilância em Saúde. Programa Nacional de DST/AIDS. Donovanose in manual de controle de Doenças Sexualmente Transmissíveis: DST. 4 ed. Brasília, DF: Série Manuais; 2006. p.68:50.

57. Belda W Jr, Velho PE, Arnone M, Romitti R. Donovanosis treated with thiamphenicol. Braz J Infect Dis. 2007;11:388-9.

ENDEREÇO PARA CORRESPONDÊNCIA / MAILING ADDRESS:
Walter Belda Junior
Av. AçOcê, 162- Moema
04075 020 São Paulo - SP
Tel./fax: 551150515141
E-mail: walterbelda@uol.com.br

Como citar este artigo/How to cite this article: Belda Jr. W, Shiratsu R, Pinto V. Abordagem nas doenças sexualmente transmissíveis. An Bras Dermatol. 2009;84(2):151-59. 